\title{
Information-processing in French Adults Practicing Deception
}

\section{Gabriella Fekete*}

Laboratoire Dynamique du Langage, Université de Lyon, France

*Corresponding author. E-mail: fekegab@gmail.com

Background. Experiences which people have and perceive personally (Skowronski et al., 1991) are interpreted in a subjective way (Weiss \& Cropanzano, 1996) and stored in autobiographical memory along with information related to their lifetime periods, general events, and event-specific knowledge (Conway \& Pleydell-Pearce, 2000; Larsen \& Thompson, 1995). These three specific knowledge-types are intertwined and come up together when an individual is recalling memories (Conway, 1996).

Objective. The aim of our study is to investigate how French adults process information in deceptive speech. We observed the information-types used in the three knowledge-types of autobiographical memory in monologs and answers to questions.

Method. Our data comes from videotaped spontaneous oral speeches produced by 17 French adults. The participants were given the task of producing a fake opinion paradigm on their favorite sport.

Result. Our results show discrepancies in the frequency of the three knowledge-types of autobiographical memory used in the true and deceptive speech of practitioners and viewers. We also found that certain informationtypes are linguistic-context-dependent while others are systemic. The findings highlight the fact that some information is missing and/or replaced, and other information is nuanced in deception compared to truthful speech.

Conclusion. This study can contribute to a better understanding of deceivers' cognitive processing, as well as demonstrating the close relationship between language and cognition.
Keywords: deception, informationprocessing, knowledge-types of autobiographical memory, monolog, questioning 


\section{Introduction}

Deception is "a successful or unsuccessful deliberate attempt, without forewarning, to create in another a belief which the communicator considers to be untrue" (Vrij, 2008, p. 15). It is a cognitively taxing task (Adams-Quackenbush, 2015; Karim et al., 2010; Vrij, 2000; Zuckerman, DePaulo, \& Rosenthal, 1981) that requires numerous cognitive processes activated non-linearly. They include: recall of past events; coherent elaboration of invented events; linguistic encoding; cognitive inhibition; and attention (Adams-Quackenbush, 2015; Buller \& Burgoon, 1996).

Research on lying has been expanding over the past decade. Studies of the verbal and nonverbal characteristics of deceptive speech have been widely investigated in the United States and the United Kingdom, and their main findings have been tested in many languages. Researchers have been interested in different verbal indicators, such as pronouns, semantic verb types, adjectives, syntactic structures, perceptual, emotional and spatial-temporal information, inter-clausal connectors, and negations (Arciuli, Villard, \& Mallard, 2009; Bond \& Lee 2005; Connelly et al., 2006; Hancock, Curry, Goorha, \& Woodworth, 2005, 2008; Johnson \& Raye, 1998; Newman, Pennebaker, Berry, \& Richards, 2003; Pennebaker, Mehl, \& Niederhoffer, 2003; Peucheret, 2014).

Verbal and nonverbal cues exclusively indicating deception do not exist (Sporer \& Schwandt, 2007; Vrij, 2005), and the cross-linguistic results are not homogeneous. This might be explained by several factors:

1. Analyzing separately linguistic units like pronouns as indicators of psychological distancing (Bond \& Lee 2005; DePaulo et al., 2003; Hauch, BlandónGitlin, Masip, \& Sporer, 2012; Mehrabian, 1971; Newman et al., 2003) leads to the loss of information carried by the linguistic context which can express the opposite (I took the money vs. I received the money by mail);

2. Cross-linguistic comparisons should take into account the different linguistic properties of the target languages; thus, generalization from findings based on the English language, such as the frequency of different semantic verb-types (action verbs vs. stative verbs), must be treated with caution (for the typology of encoding systems of motion events, see Talmy, 1985);

3. Different-corpus-based results are not always comparable: for example, spontaneous or prepared oral narratives (Mihalcea \& Strapparava, 2009) or interactions (Hancock et al., 2005); interview dialogues (Levitan, Maredia, \& Hirschberg, 2018); written narratives (DeCicco \& Schafer, 2015); or computer-mediated written interactions like emails and sms (Dou, Liu, Muneer, \& Schlussel, 2017; Zhou, Burgoon, \& Twitchell, 2003)

In the present paper, we consider deceptive speech as a whole, and observe it from a macrostructural perspective. Deceptive speech generally contains $95 \%$ truth, but the deceiver prepares his 5\% untruth from the beginning of his/her speech. Consequently, this mental preparation affects all his/her cognitive processes, and thus the structuring of his/her entire story, including the true parts.

We tend to investigate how lying speakers verbally build up experiences and reasoning, taking into consideration linguistic- and extra-linguistic-contextual factors. It is very important to capture the different types of information the deceiver 
uses to keep psychological distance regarding events. The cognitive processes that are reflected in his/her language use could let us get closer to the deceiver's way of thinking.

First, we discuss previous findings on the storage of lived experiences in the memory and the macro-structural markers used in deceitful speech. After presenting our assumptions and describing the methodology used to collect and process the spoken data, we will describe all the alternative information-types found in the three knowledge-types of autobiographical memory in the French adults' speeches. Note that our aim is not to propose a new method for detecting deception. We are interested in how the deceivers process information.

\section{Personal experiences in memory}

Events are lived and interpreted in a subjective way according to both individual and contextual factors (Weiss \& Cropanzano, 1996) and stimulate the affective system (Forgas, 1999). Both personally-lived (self-events) and -perceived experiences (other-events) (Skowronski, Betz, Thompson, \& Shannon, 1991) are encoded and stored in autobiographical memory (Larsen \& Thompson, 1995). The encoded information does not uniquely consist of the event itself, but is associated with other related information such as the context and the individual's affective state (Geiselman, Fischer, Cohen, Holland, \& Surtes, 1986). Autobiographical memory stores three specific knowledge-types: those related to lifetime periods $=(1 \mathrm{a})$; general events $=(1 \mathrm{~b})$; and event-specific knowledge $=(1 \mathrm{c})$ (Conway \& PleydellPearce, 2000). For example:

When I was young (1a), we had a big garden (1b); I often played on a swing there (1c) and I was always afraid of falling down (1c).

These knowledge-types are inter-connected and emerge together when an individual is recalling specific autobiographical memories (Conway, 1996).

Event-specific knowledge, including sensory-perceptual experiences, plays a key role in distinguishing perceived events from imagined events (Conway, Collins, Gathercole, \& Anderson, 1996). According to Johnson and Raye (1981), perceived experience should be stored with more perceptual and contextual information and meaningful details in the memory; conversely, an imagined event should contain more information about cognitive operations.

Deceptive discourse is essentially generated by cognitive operations and comprises unlived experiences; therefore, it is generally composed in a vague and less detailed way (Johnson \& Raye, 1998; Porter \& Yuille, 1996; Vrij, 2000). It is less coherent and syntactically less complex (Newman et al., 2003; Porter \& Yuille, 1996). It contains more pauses, word repetitions, and speech disturbances (DePaulo et al., 2003; Mann, Vrij, \& Bull, 2002; Vrij, 2008). The reaction time of deceivers is longer (Farrow et al., 2003; Walczyk, Roper, Seemann, \& Humphrey, 2003). "Untrue speech" is generally less plausible, with more words expressing negative emotion (Newman et al., 2003). There is no consensus on production length (Granhag \& Stromwall, 2002; Hancock et al., 2008; Sapir, 1996).

$\mathrm{Li}$ and Santos $(2011,2012)$ have addressed the issue of deception cues from another perspective. They tried to retrieve the reasoning process of deceivers using natural language-processing techniques applied to the data. Truth-tellers' and 
deceivers' reasoning may show discrepancies because their basic belief systems are not similar. Their results suggest that the deceptive reasoning is built up from arguments based on presuppositions. These arguments are closely related to each other, and serve the deceiver's purpose.

In the present paper, we try to investigate the deceiver's expression of experiences and reasoning in order to capture discrepancies in his/her way of thinking. We will analyze deceptive speech in four types of situation: 1) spontaneous monologs; 2) answers to questions requiring feelings; 3 ) the reasoning processes of truth-tellers and deceivers who affirm having lived experiences; and 4) of those who pretend to have had perceived experiences.

\section{Research questions}

The aim of our study is to observe the reflection sequences of truth-tellers and deceivers in order to detect discrepancies in their belief systems regarding events presented in deceptive speech, as compared to true speech.

Previous findings suggest that the three knowledge-types (lifetime periods, general events, and event-specific knowledge) of autobiographical memory are inter-connected (Conway, 1996), and event-specific knowledge is a main characteristic of really lived and perceived experience (Conway et al., 1996). This latter experience-type is stored with more perceptual and contextual details in the memory (Johnson \& Raye, 1981). In deception, the three knowledge-types are not stored and cannot be recalled. Consequently, deceptive speech is mainly based on cognitive operations (Johnson \& Raye, 1981) and presuppositions (Li \& Santos, 2011, 2012) with fewer perceptual and contextual details (Johnson \& Raye, 1981, 1998; Porter \& Yuille, 1996; Vrij, 2000) and more negative affect (Newman et al., 2003).

Based on the results of these studies we hypothesized that:

- The synchronic presence of the three knowledge-types of autobiographical memory, but primarily event-specific knowledge, should appear infrequently in a deceptive reflection sequence.

- Individuals who truly lived an experience should express more specific details on events related to themselves. Individuals who truly perceived an experience should describe more context-detailed information. However, individuals who falsely affirm personally experienced events should give more general, cognitively-deduced information.

- Lifetime-period-knowledge should be primarily mentioned in the case of past experience in monologs or answers to questions oriented to this information-type. Continuous and/or repetitive experience does not require this knowledge-type.

- Event-specific knowledge is stored with personal feelings which are missing in unlived experience. Consequently, more affective information should occur in deception to compensate for this lack. Note that affective information is a subjective evaluation-type referring to a specific event. However, a general situation also can be evaluated. This latter is separated from the former with nuanced linguistic tools. So, a situational evaluation can hide the untrue nature of information which can be merged with affective evaluation. Consequently, this evaluation-type should appear more often in deception. 


\section{Method}

\section{Speakers}

Videotaped data were collected from 17 monolingual native French speakers, twelve women and five men. The mean age was 28.07 years (19.03-55.09). The speakers were selected based on their willingness to perform the task. There was no qualification as to sex or education. They knew neither the aim of the study nor what they would be asked to do.

\section{Task}

The task used to obtain the texts was a fake opinion paradigm on a favorite sport. This method has already provided the basis for several previous studies (Newman et al., 2003; Mihalcea \& Strapparava, 2009). The participants were asked to relate truthful and deceptive positive opinions about sports that they like and dislike. Sports were chosen as the main topic because all study participants were sportspersons.

We needed a comparable "norm", namely the linguistic dynamics of truthful speech, in order to investigate the deceptive speech. Consequently, the task consisted of two parts: a discussion about the participant's favorite sport (the "true part"), and then another discussion about the participant's least favorite sport, which was introduced as his/her favorite one (the "deceptive part"). We began the task with the true monologs for two main reasons: on the one hand, to allow the participants to feel at ease with a familiar topic (Burgoon \& Qin, 2006), and on the other hand, to increase their cognitive load with unexpected questions (Tekin et al., 2015) and then a deception request thereafter. The monologs were followed by questions in both parts.

It is important to emphasize that the aim of the study was to get the participants to talk, so that we could observe the linguistic and cognitive characteristics of their deceptive speech. Deception detection was not an objective of the present study.

A comparison of the two discourse-types (monologs and answers) can reveal interesting discrepancies because individuals telling the "untruth" do not organize the flow of information in the same way as when they are telling the truth. Thus, deceivers possess "freedom of expression" without any particular orientation in monolog. It follows that they can arbitrarily decide which information and details to tell. Thus, they expect to draw attention to the true parts of their story. However, questioning imposes on them a specific orientation with cognitive constraints which deprives them of their "expressive freedom".

Depending on their answers to the question Do you practice this activity?, the participants were classified as either practitioners or viewers.

\section{Protocol}

The discussion had been conducted by the author. The same protocol was used for all participants. They were interviewed individually in an isolated room at their workplace. The office walls were uniformly painted white, with neither pictures nor patterns on the walls. The interviewer and the participant sat face to face without anything between them. The participant was placed with his/her back to the window and/or the door. This allowed us to avoid any cognitive bias. 
The introduction of the task consisted of several steps.

First, the researcher started a discussion in order to defuse tension and get the participant to forget the camcorder. Then she asked him/her to talk about his favorite sport. Once the participant had finished his/her monolog, the investigator asked questions such as: What do you like about this activity? How often do you do it in a week? With whom do you practice? Do you compete? Can you quote me some game rules?

After the questioning, the researcher asked the participant to stand up, take a walk around the chair, and again to be seated, in order to get him/her out of the truth-telling, corporal, and cognitive dynamics. Then the investigator requested him/her to talk about the sport he/she likes least, but as if it were his/her favorite sport. The interviewer never mentioned the word "lie" because the direct request to "sell" a story causes participants to outperform. The subsequent questioning of the participant about his/her deception was comprised of questions similar to those asked about the truth.

\section{Transcription and coding}

The recorded productions were transcribed, segmented into clauses, coded, and analyzed by the author. A clause is a unit that contains a predicate (an inflected [2a] or non-inflected [2b] verb, or a predicative adjective [2c]). The predicate should describe a situation (activity, event, state) (Berman \& Slobin, 1986). Examples of the coding follow:

(2) a. Donc aujourd'hui, je fais plus mon sport préféré.

1 clause

'So nowadays, I do not do my favorite sport anymore.'

(Quentin, Truth, 00:38-40)

b. Je viens de partir en Autriche. / Skier.

2 clauses

'I just went to Austria. / Skiing.'

(Dorian, Truth, 00:53-56)

c. Et puis en général, l'ambiance autour d'un match

1 clause

est plutôt intéressante aussi.

'And then in general, the ambience around

a match is rather interesting too.'

(Jeanne, Deception, 4:09-13)

This minimal unit was adopted because oral speech often comprises a succession of clauses (rather than sentences) whose start and end are difficult to determine.

One-way and two-way analysis of variance measuring deception, "expressive freedom", and experience-type effects have been calculated for checking on the effect-relatedness of results. The quantified data represent the mean percentages.

\section{Information-types}

We identified ten information-types within the whole body of data.

We labeled lived experiences ( $3 a$ ) as all factual information related to personal practice, and perceived experiences $(3 \mathrm{~b})$ as practice's follow-up, such as watching tv. For example: 
(3) a. J'en ai fait pendant 10 ans à Bron jusqu'en Championnat de France. 'I had done for 10 years in Bron until France Championship.' (Kahina, Truth, 00:39-44)

b. Quand tu vois un match de rugby.

'When you are watching a rugby match'.

(Arthur, Deception, 03:09-03:10)

Contextual information (4) described all general information not directly related to the personal experience but to the environment in which the experience took place.

(4) Donc il y a pas besoin de... 50,000 accessoires.

'So, there is no need for... 50,000 accessories.'

(Nadège, Truth, 01:06-10)

We distinguished feeling and affect. We considered as personal feeling (5a) an event-specific sensation provoked by lived and perceived experience. However, affect (5b) is part of an event-general evaluation. A general-situational evaluation $(5 c)$ is coded as evaluation.

(5) a. J'évacue... toutes les mauvaises ondes. 'I evacuate all the bad vibes.' (Adeline, Truth, 00:31-00:34)

b. J'aime bien ce sport. 'I like this sport.' (Clémentine, Deception, 02:56-57)

c. Et c'est vraiment génial avec les compétitions et tout. / C’est super. 'And it is really great with competitions and all. / It is super.' (Gaëlle, Deception, 02:57-03:00)

We also identified aptitude information (6) such as body control, endurance, rigor, and team spirit which describe the physical and mental skills developed through practice. This information-type can be related either to general-event knowledge in a truthful speech, or to a supposition deduced from general cognitive knowledge in deception.

(6) Il faut beaucoup de concentration. / Etre très méticuleux.

'It requires a lot of concentration. / One should be very meticulous.'

(Laetitia, Deception, 03:50-03:54)

Bodily information (7) refers to the corporal properties of individuals or the corporal effects of practice.

(7) Bah physiquement ça muscle vraiment harmonieusement le corps, le dos.

'Well physically, it strengthens really harmoniously the body, the back.'

(Jeanne, Deception, 03:40-03:44)

The last information-type is technical information (8). We consider it as eventspecific knowledge related to sport-type.

(8) Vu que c'est le ballon. / Qui est en l'air. / C'est quand-même... aérodynamique. 'Because this is the ball. / That is in the air. / It is anyway aerodynamic.'

(Alizée, Truth, 01:16-01:19) 


\section{Results}

\section{Information-types in Monologs}

Figure 1 displays the different information-types found in the monologs of the French speakers who affirmed a lived experience.

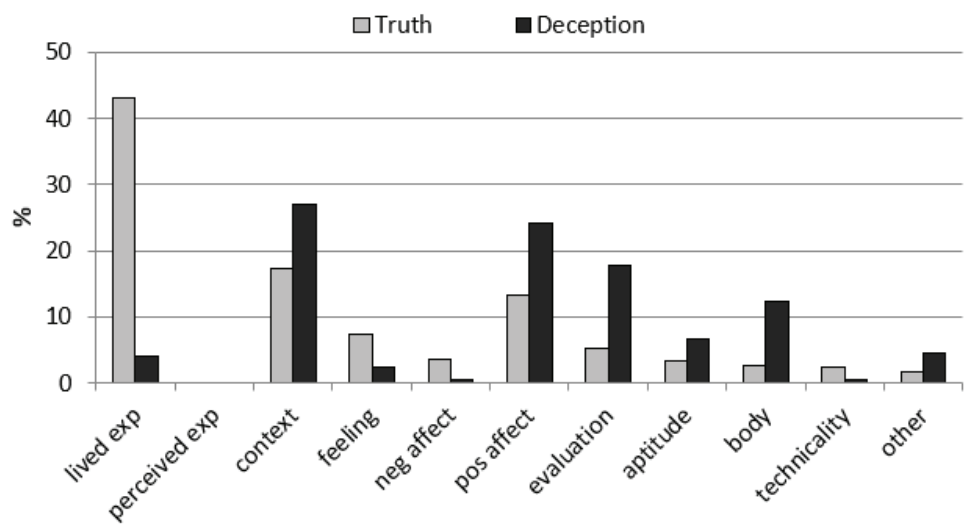

Figure 1. Information-types in monologs of French speakers practicing their favorite sport.

Figure 1 reveals that personal facts about lived experience are spontaneously mentioned more in true discourse $(F(1,23)=14.85, p=.0008)$ than in deception. Both general-situational evaluation and bodily information score significantly higher in deceptive speech $(F(1,23)=16.61, p<.02$ and $F(1,23)=5.68, p<.03$, respectively). Other speech characteristics appear with similar frequency in both truthful and deceptive monologs.

Figure 2 shows the different information-types found in the monologs of the French speakers who affirmed perceived experience.

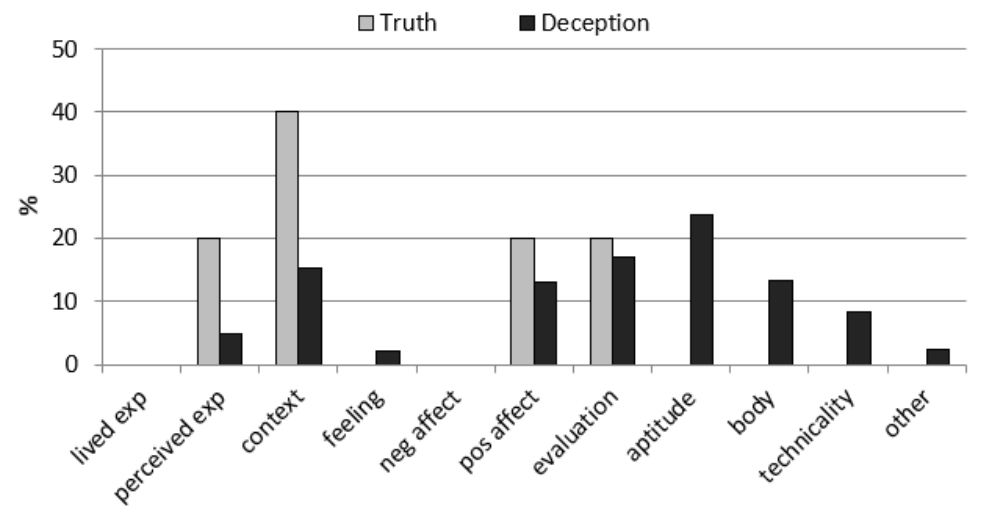

Figure 2. Information-types in monologs of French speakers viewing their favorite sport.

Although one-way analysis of variance shows no deception-related effect, truth-tellers who perceptually experience specific events talk about their perceived experience and environmental context more often than deceivers do. It is notable that aptitude-, body- and technicality-information are mentioned only in deceiv- 
ers' monologs about supposed perceived-experience. The frequency of positive affect and evaluation is similar in truth and in deception.

In sum, true monologs contain significantly more lived experiences $(F(1,27)=16.88, p=.0003)$ than deceptive discourse. Perceived experiences do not show discrepancies according to deception-effect $(F(1,27)=0.004, p=\mathrm{NS})$. Therefore, they appear significantly more often in viewers $(F(1,27)=33.94, p<.0001)$ than in practitioners. Two-way analysis reveals an interaction between deception and perceived-experience effects $(F(1,25)=93.46, p<.0001)$. This means that viewers telling the truth give information about perceived experience significantly more often than practitioners or deceptive viewers do in their monologs. No difference is found in the frequency of contextual information, feeling, and negative and positive affect. Evaluative information is impacted by deception-effect $(F(1,27)=6.86$, $p<.02)$ but not the experience-type effect $(F(1,27)=1.18, p=N S)$ in the French monologs of our data. There is no interaction between the two factors.

Deception has no effect on aptitude information $(F(1,27)=2.42, p=\mathrm{NS})$. Therefore, one-way analysis of variance with experience-type effect shows that there is generally a tendency for viewers to give aptitude-information $(F(1,27)=3.72, p<.07)$. The global deception effect on body-information is significant $(F(1,27)=7.58$, $p<.02)$ in the monologs. Thus, deceivers-practitioners as well as viewers-tend to evoke physical aspects more often than truth-tellers do. Technicality occurs with similar frequency in both truthful and deceptive discourse.

\section{Information-types in Answers}

In order to obtain comparable data, we investigated the answers to Wh-questions that involve the speaker and require event-specific feeling-information with some reasoning. We chose reactions to the questions: What do you like about this sport? What does this activity bring to you physically and mentally?

Figure 3 illustrates the information-types produced by the French speakers as supposed practitioners during questioning.

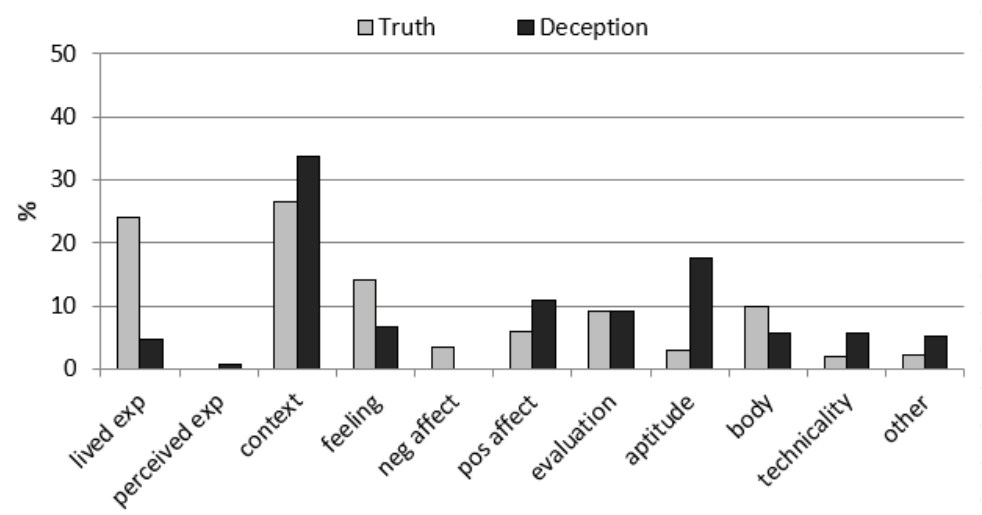

Figure 3. Information-types used in answers by French speakers practicing their favorite sport.

Real practitioners tend to mention lived experience more often $(F(1,14)=4.37$, $p<.06)$ than false practitioners do. One-way analysis of variance with deception effect shows no significant effect for all the other aspects. 
Figure 4 displays the information-types which occur in the French viewers' answers.

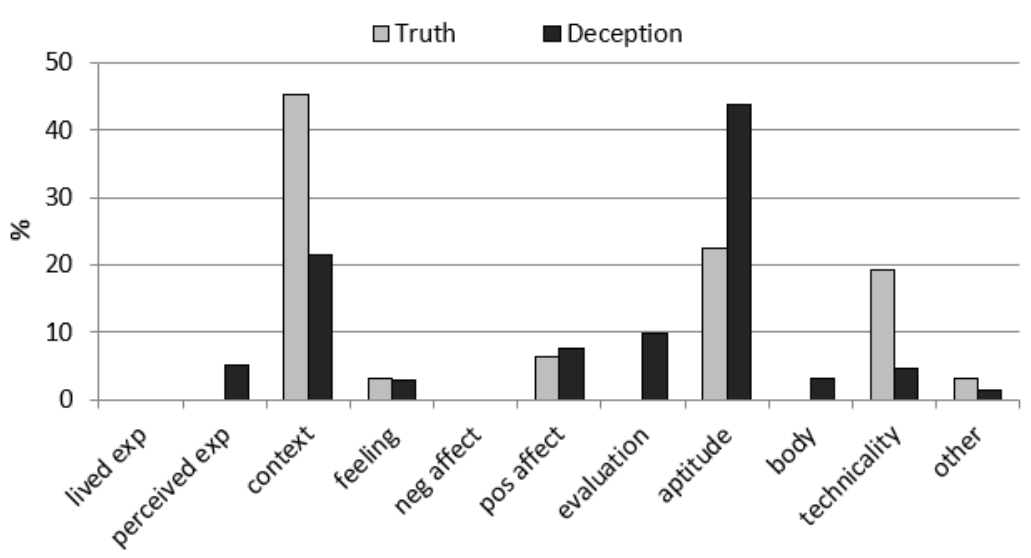

Figure 4. Information-types used in answers by French speakers viewing their favorite sport.

There is a preference for contextual information in true answers. Its frequency increases in truth-tellers and decreases in deceivers, compared to practitioners. Only untrue viewers evaluate general situation during questioning. Deceivers favor aptitude-information which shows up more often in both truthful and deceptive viewers than in practitioners. Technical information is primarily expressed in true speech. One-way analysis of variance with deception-effect shows no significance for all the information-types.

In sum, true answers to feeling-oriented questions generally contain significantly more lived experiences $(F(1,19)=5.22, p<.04)$ than do false answers, irrespective of experience-type. The French speakers of our data similarly mention aptitude in both true and deceptive answers, but this information-type is significantly more frequent in viewers $(F(1,19)=5.5, p=.03)$ than in practitioners.

\section{Information-types in Monologs and Answers}

Generally speaking, certain information-types are linguistic-context-dependent while others are systemic.

Lived experience scores significantly higher in true $(F(1,48)=25.22, p<.0001)$ than in deceptive speech. It has a tendency to be produced more in monologs $(F(1,48)=3.86, p<.06)$ than during questioning. Lived experience is only present in practitioners' data of our corpus, and it is significantly related to this experiencetype $(F(1,48)=5.12, p<.03)$. No interaction is observed between the three factors (deception, expressive freedom, and practice). Neither deception $(F(1,48)=0.34$, $p=\mathrm{NS})$ nor expressive-freedom effects $(F(1,48)=0.01, p=\mathrm{NS})$ are significant for perceived experience. Therefore, this information-type appears significantly more often in viewers $(F(1,48)=19.65, p<.0001)$ than in practitioners.

Our French speakers give contextual information and talk about their feelings in a similar way in truth and deception, monologs and answers, and lived and perceived experiences. Negative affect is expressed significantly more often in true monologs and answers $(F(1,48)=5.94, p<.02)$. Neither deception nor ex- 
perience-type effects have an impact on positive affect $(F(1,48)=1.1, p=\mathrm{NS}$ and $F(1,48)=0.46, p=\mathrm{NS}$, respectively), which is rather influenced by expressive freedom. It is significantly more frequent in monologs $(F(1,48)=4.72, p<.04)$.

Evaluative information tends to be used more in deception $(F(1,48)=3.97$, $p<.06)$ than in truth. Aptitude scores significantly higher in deceptive $(F(1,48)=7$, $p<.02)$ than in truthful speech; in answers $(F(1,48)=4.8, p<.04)$ rather than in monologs; and in viewers $(F(1,48)=11.14, p<.002)$ rather than in practitioners. The three factors act independently. The French practitioners and viewers in our study talk about physical properties and effects, and give technical information similarly in truthful and deceptive speech, and monologs and answers.

\section{Autobiographical Knowledge-types in Monologs}

In order to study different autobiographical knowledge-types, we separated individuals who currently practice a given sport from those who have stopped the activity.

We considered context-, aptitude- and body-information as general-event knowledge, and lived and perceived experiences, feeling- and technicality-information as specific-event knowledge. Given that affect is an evaluation-type, we classified it with general-situational evaluation.

Figure 5 shows autobiographical knowledge-types expressed in the monologs of the French current-practitioners.

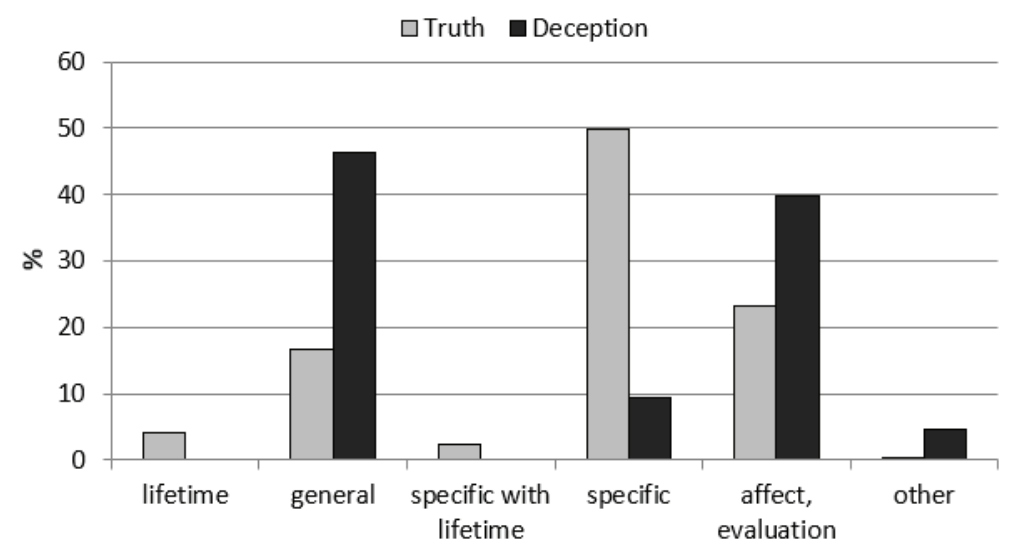

Figure 5. Autobiographical knowledge-types in the monologs of French current-practitioners.

Figure 5 reflects the fact that lifetime period, general- and specific-event knowledges are synchronically present when French truth-tellers talk about their current activity in monologs. They rarely mention the lifetime period in a single clause or integrated within a specific-event (9).

(9) Depuis toute petite, je monte à cheval.

'Since childhood, I ride.'

(Clémentine, Truth, 00:35 - 00:37)

It is important to note that reference to a lifetime period is only found in true speech in our current-activity data. One-way regression analysis signals a truth- 
tendency for both this knowledge-type $(F(1,21)=3.43, p<.08)$ and its integration into a specific event $(F(1,21)=4.12, p<.06)$. General-event knowledge occurs significantly more often in deception $(F(1,21)=13.52, p<.002)$ than in a truthful monolog. Specific-event knowledge is significantly more frequent in true discourse $(F(1,21)=30.15, p<.0001)$ than in deceptive monolog.

Figure 6 shows the autobiographical knowledge-types which appear in the monologs of French past-practitioners.

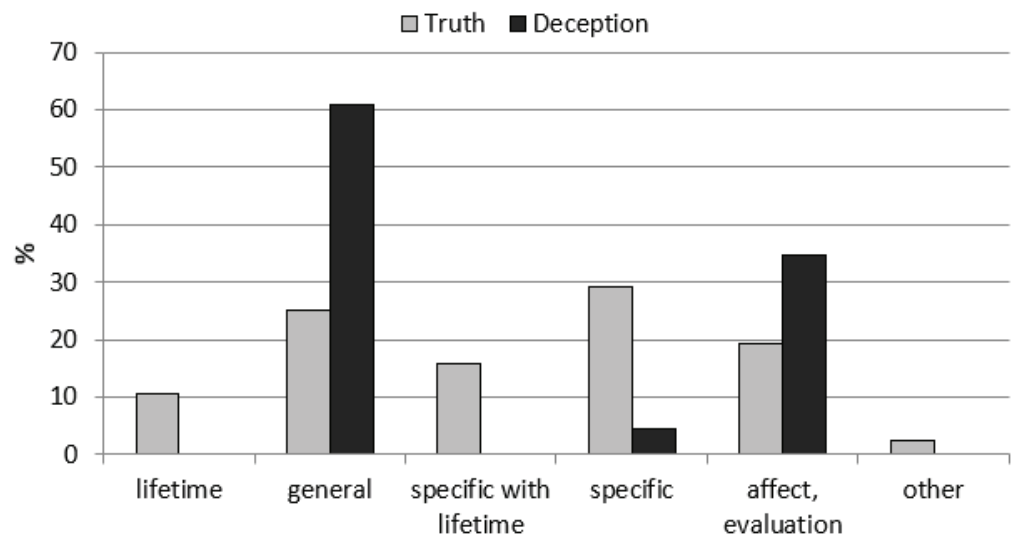

Figure 6. Autobiographical knowledge-types in the monologs of French past-practitioners.

The synchronic presence and frequency of the three knowledge-types in the past-practitioners' monologs demonstrate the same tendency as those in currentpractitioners. The lifetime period only occurs in true discourse in a single clause or integrated within a specific-event, and it occurs more often for past-activity than for current-activity. General-event scores higher in deceivers' monologs $(F(1,10)=2.03, p=\mathrm{NS})$, and specific-event is more frequent in truth-tellers' discourse $(F(1,10)=1.37, p=\mathrm{NS})$, but these differences are not significant. As in current-activity, the expression of both affect and evaluation is more frequent in deception. One-way analysis of variance found no deception-effect on all the speech characteristics.

As for autobiographical knowledge-types viewed generally, the mention of lifetime events in a single clause and specific events connected with lifetime-periods only occur in truth-tellers. A lifetime period cited in a single clause is true$(F(1,33)=5.71, p<.03)$ and past-related $(F(1,33)=5.71, p<.02)$. A lifetime period embedded within a specific event is not impacted by the truth-effect $(F(1,33)=2.33$, $p=\mathrm{NS}$ ); therefore, it occurs significantly more often in past-practitioners' monologs $(F(1,33)=5.38, p<.03)$. General-event scores significantly higher in deceptive speech $(F(1,33)=13.34, p=.0009)$ than in true monologs in both current- and pastactivities $(F(1,33)=0.21, p=\mathrm{NS})$. French truth-tellers talk about specific-events significantly more often in monologs $(F(1,33)=19.34, p=.0001)$ than French deceivers do, in both current- and past-activities $(F(1,33)=0.31, p=N S)$. Affective and evaluative expressions are significantly more frequent in deception $F(1,33)=5.35, p<.03)$, and have a tendency to occur most often in current-activities $(F(1,33)=3.73, p<.07)$. 


\section{Discussion}

Our main results show discrepancies in true and deceptive speech. French speakers refer more often to a lifetime period when recalling personally lived past events. This finding supports our hypothesis on the past-related significance of lifetime period knowledge. Thus, ongoing activities are actually related to the present; therefore, they do not need to be specified. Only truth-tellers talk about this knowledgetype, and mainly in a single separated clause, and recall more specific-events for both current- and past-activities than deceivers do.

These results confirm our hypothesis which expected that the frequency of synchronic presence of the three knowledge-types should be lower in deceptive discourse, and specific-event knowledge higher in truthful speech. This is an individual-related factor. Deceivers who did not personally live the experience did not systematically store information in memory. To fill this lack, they give more general event-information and do more evaluation of events and situations. These two information-types will be discussed in more detail later.

Generally speaking, certain information-types are related to linguistic context, while others seem to be systemic.

Lived experience occurs more often in truthful than in deceptive speech, more in monologs than answers, and more in practitioners than in viewers. Perceived experience is expressed more often in viewers than in practitioners. Thus, lived events are always interpreted and stored from an individual point of view (Forgas, 1999; Skowronski et al., 1991; Weiss \& Cropanzano, 1996) based on the individual's own sensory and corporal experiences due to embodiment (Barsalou, 2008 ; Niedenthal, Barsalou, Winkielman, Krauth-Gruber, \& Ric, 2005).

Negative affect characterizes truthful speech while positive affect is related to the expressive freedom of monologs. These findings do not confirm our hypotheses and previous research on the higher score for negative and positive affect in deception (DePaulo et al., 2003; Newman et al., 2003). The more frequent negative affect in true discourse could be due to the fact that truth-tellers do not hesitate to express deprecation of some event-aspects. Deprecation is natural. However, deceivers could believe that expressing negative affect could betray their false discourse.

Evaluative information tends to occur more in deception, in accord with our hypothesis. Evaluation is part of cognitive appraisal, including reasoning. Deceivers want not only to convince their interlocutor about the truthfulness of their story, but also to close the topic with an evaluative conclusion. We are on a tatami. It is cool. (Jérémy, Deception). Interrogators rarely request reasoning after such an evaluation (Why is it cool?).

Aptitude is more frequent in deception, appears more in answers, and viewers express it more than practitioners. We suggest that aptitude is a deduction via general cognitive knowledge, and that it is an alternative to reasoning (if necessary) because it is feeling-like. Take the interchange: Q: What do you like in this activity? A. That one must be rigorous. The interrogator considers rigor a positive affect by association, which is an erroneous cognitive process. Can we like an activity for the aptitude it requires? Particular activities require aptitudes for better performance, but it is not necessary for practice. However, certain activities provoke intimate 
sensations and feelings that emerge only during their practice. Consequently, we propose that deceivers justify appreciation either with feelings transferred from a real experienced activity, or with an aptitude, if they already had a perceived experience with the activity.

Our French speakers (especially the truth-tellers) with perceived experience obviously expose these experiences in their monologs. They also give more aptitude-information than speakers with lived experience. Monologs by real practitioners contain more lived experiences. Deceivers, in contrast, evaluate general situations and discuss corporal aspects more often than truth-tellers do in their monologs. During feeling-oriented questioning, true answers contain more lived experiences, and viewers talk about aptitude more often than practitioners do.

Contextual-, feeling- and technical-information seem to be systemic with no discrepancy based on deception, expressive-freedom, and experience-type effects, according to our results. These results can be explained by the fact that neither context nor technicalities require experience. Each individual can know them through his general knowledge. As for feeling, it is not often expressed; it is part of the intimate sphere that individuals may not like to expose.

Table 1 summarizes information-types with their different effects found in the data produced by our French participants.

Table 1

Impact of different effects on information types found in French monologs and answers

\begin{tabular}{|c|c|c|c|}
\hline & Deception & Expressive freedom & Experience-type \\
\hline \multicolumn{4}{|c|}{ Lifetime-period knowledge (truth- and past-related) } \\
\hline \multicolumn{4}{|c|}{ General-event knowledge (deception-related) } \\
\hline Context & - & - & - \\
\hline Aptitude & deception & answer & viewer \\
\hline Body & in deceptive monolog & - & - \\
\hline \multicolumn{4}{|c|}{ Specific-event knowledge (truth-related) } \\
\hline Lived experience & truth & monolog & practitioner \\
\hline Perceived experience & - & - & viewer \\
\hline Feeling & - & - & - \\
\hline Technicality & - & - & - \\
\hline \multicolumn{4}{|c|}{ Evaluation (deception- and current-related) } \\
\hline Negative affect & truth & - & - \\
\hline Positive affect & - & monolog & - \\
\hline General evaluation & deception & - & - \\
\hline
\end{tabular}




\section{Conclusion}

Our aim in this paper was to observe how French speakers manage informationprocessing in deceptive monologs and answers when recounting personally lived or perceived experiences. Our data are composed of spontaneous spoken speeches produced by 17 French adults.

The results reveal important aspects of the speakers' way of thinking in deception, which is multi-faceted and extremely sensitive to linguistic and extra-linguistic context. Events lived or perceived personally generate specific details stored in memory that French deceivers do not provide in spontaneous oral speech. In addition, they use both linguistic and cognitive subtleties to counter an interlocutor's suspicion. Thus, some information is missing and/or replaced, and other information is nuanced in their deceptive speech.

A multidisciplinary approach provides relevant support for tracking the characteristics of deceptive language and cognition because there is a bidirectional interaction between them. Deceivers' reflection sequences are reflected in the linguistic tools they use. On the other hand, their language modulates their perception of the world (Berman \& Slobin, 1994; Whorf, 1956). Consequently, future studies should take into account the specific features of both the target language and culture.

\section{Limitations}

Although our results provide relevant points and a guideline for future research on information-processing in deception, we have identified some limitations.

First, our separation of lived and perceived experience-data was based on the speakers' answers to the question Do you practice this activity?. The majority affirmed they were practitioners in both the truth and deception tasks. Consequently, the sample size of the two experience-types was not well-balanced, which can explain the lack of significant results for perceived experience.

Second, some results, like positive and negative affect, could have been impacted by the fact that the experimental task-type was emotionally charged. Deceivers were asked to talk about their least favorite sport as if it were their most favorite one. This request can be interpreted as excluding negative affect and highlighting the positive one.

Finally, we did not separate affirmation and argumentation in our analysis. Indeed, there is a huge difference between The weekend is the moment for matches (Alizée, Truth) and I like running because it is free (Julie, Deception). Consequently, this generalized treatment can hide the visibility of the effect-significance of certain information-types such as context, feeling, and technicality.

\section{References}

Adam-Quackenbush, N.M. (2015). The Effects of Cognitive Load and Lying Types on Deception Cues (Doctoral dissertation). Saint Mary's University, Halifax, Nova Scotia. Retrieved from: https://www.researchgate.net/profile/Nicole_Adams-Quackenbush/ publication/282706149_The_Effects_of_Cognitive_Load_and_Lying_Type_on_Deception_Cues/links/562374b008ae93a5c92b6c66/The-Effects-of-Cognitive-Load-and-LyingType- on-Deception-Cues.pdf 
Arciuli, J., Villar, G., \& Mallard, D. (2009). Lies, Lies and More Lies. In N. Taatgen \& H. van Rijn (Eds.), Proceedings of the 31st Annual Conference of the Cognitive Science Society (pp. 23292334). Red Hook, NY: Curran Associates, Inc.

Barsalou, L.W. (2008). Grounded cognition. Annual Review of Psychology, 59, 617-645. https:// doi.org/10.1146/annurev.psych.59.103006.093639

Berman, R.A. \& Slobin, D.I. (1986). Frog story procedures in coding manual: Temporality in discourse. Institute of Human Development, University of California at Berkeley.

Berman, R.A. \& Slobin, D.I. (Eds.) (1994). Relating events in narrative: A crosslinguistic developmental study. Hillsdale, NJ: Lawrence Erlbaum.

Bond, G. \& Lee, A.Y. (2005). Language of Lies in Prison: Linguistic Classification of Prisoners' Truthful and Deceptive Natural Language. Applied Cognitive Psychology, 19, 313-329. https://doi.org/10.1002/acp.1087

Buller, D.B. \& Burgoon, J.K. (1996). Interpersonal deception theory. Communication Theory, 3, 203-242. https://doi.org/10.1111/j.1468-2885.1996.tb00127.x

Burgoon, J. \& Qin, T. (2006). The dynamic nature of deceptive verbal communication. Journal of Language and Social Psychology, 25, 76-96. https://doi.org/10.1177/0261927X05284482

Connelly, S., Allen, M.T., Ruark, G.A., Kligyte, V., Waples, E.P., Leritz, L.E., \& Mumford, M.D. (2006). Exploring content coding procedures for assessing truth and deception in verbal statements, year 3, cumulative final report. Norman, OK: University of Oklahoma.

Conway, M.A. (1996). Autobiographical memories and autobiographical knowledge. In D.C. Rubin (Ed.), Rememberingourpast: Studies in autobiographical memory (pp. 67-93). Cambridge, England: Cambridge University Press. https://doi.org/10.1017/CBO9780511527913.003

Conway, M.A., Collins, A.F., Gathercole, S.E., \& Anderson, S.J. (1996). Recollections of true and false autobiographical memories. Journal of Experimental Psychology: General, 125, 69-95. https://doi.org/10.1037/0096-3445.125.1.69

Conway, M.A. \& Pleydell-Pearce, C.W. (2000). The Construction of Autobiographical Memories in the Self-Memory System. Psychological Review, 107(2), 261-288. https://doi. org/10.1037/0033-295X.107.2.261

DeCicco, A.J. \& Schafer, J.R. (2015). Grammatical Differences between Truthful and Deceptive Narratives. Applied Psychology in Criminal Justice, 11(2), 75-92.

DePaulo, B.M., Lindsay, J.L., Malone, B.E., Muhlenbruck, L., Charlton, K. \& Cooper, H. (2003). Cues to deception. Psychological Bulletin, 129, 74-118. https://doi.org/10.1037/00332909.129.1.74

Dou, J., Liu, M., Muneer, H., \& Schlussel, A. (2017). What Words Do We Use to Lie?: Word Choice in Deceptive Messages. arXiv: 1710.00273 [cs. CL]. Retrieved from: https://arxiv. org/ftp/arxiv/papers/1710/1710.00273.pdf

Farrow, T.F.D., Reilly, R., Rahman, T.A., Herford, A.E., Woodruff, P.W.R., \& Spence, S. A. (2003). Sex and personality traits influence the difference between time taken to tell the truth or lie. Perceptual and Motor Skills, 97, 451-460. https://doi.org/10.2466/pms.2003.97.2.451

Forgas, J.P. (1999). On feeling good and being rude: Affective influences on language use and request formulations. Journal of Personality and Social Psychology, 76, 928-939. https://doi. org/10.1037/0022-3514.76.6.928

Geiselman, R.E., Fisher, R.P., Cohen, G., Holland, H., \& Suites, L. (1986). Eyewitness responses to leading and misleading questions under the Cognitive Interview. Journal of Police Science and Administration, 14(1), 31-39. NCJ Number: 142377

Granhag, P.A. \& Stromwall, L.A. (2002). Repeated interrogations: Verbal and nonverbal cues to deception. Applied Cognitive Psychology, 16, 243-257. https://doi.org/10.1002/acp.784

Hancock, J.T., Curry, L.E., Goorha, S., \& Woodworth, M. (2005). Lies in Conversation: An Examination of Deception Using Automated Linguistic Analysis. In K. Forbus, D. Gentner \& 
T. Regier (Eds.), Proceedings of the 26th Annual Conference of the Cognitive Science Society (pp. 534-539). Mahwah, NJ: Lawrence Erlbaum Associates, Inc.

Hancock, J.T., Curry, L.E., Goorha, S., \& Woodworth, M. (2008). On Lying and Being Lied To: A Linguistic Analysis of Deception in Computer-Mediated Communication. Discourse Processes, 45(1), 1-23. https://doi.org/10.1080/01638530701739181

Hauch, V., Blandón-Gitlin, I., Masip, J., \& Sporer, S.L. (2012). Linguistic Cues to Deception Assessed by Computer Programs: A Meta-Analysis. Proceedings of the EACL 2012 Workshop on Computational Approaches to Deception Detection. Avignon: Association for Computational Linguistics, 1-4. ISBN 978-1-937284-19-0

Johnson, M.K. \& Raye, C.L. (1981). Reality monitoring. Psychological Bulletin, 88, 67-85. http:// dx.doi.org/10.1037/0033-295X.88.1.67

Johnson, M.K. \& Raye, C.L. (1998). False memories and confabulation. Trends in Cognitive Science, 2, 137-145. https://doi.org/10.1016/S1364-6613(98)01152-8

Karim, A.A., Schneider, M., Lotze, M., Veit, R., Sauseng, P., Braun, C., \& Birbaumer, N. (2010). The Truth about Lying: Inhibition of the Anterior Prefrontal Cortex Improves Deceptive Behavior. Cerebral Cortex, 20(1), 205-213. https://doi.org/10.1093/cercor/bhp090

Larsen, S.F. \& Thompson, C.P. (1995). Reconstructive memory in the dating of personal and public events. Memory and Cognition, 23, 780-790. https://doi.org/10.3758/BF03200929

Levitan, S.I., Maredia, A., \& Hirschberg, J. (2018). Linguistic Cues to Deception and Perceived Deception in Interview Dialogues. Proceedings of NAACL-HLT, 1941-1950. https://doi. org/10.18653/v1/N18-1176

Li, D. \& Santos, Jr., E. (2011). Deception Detection in Human Reasoning. Proceedings of the IEEE International Conference on Systems, Man and Cybernetics. Anchorage, Alaska, USA, October 9-12, 165-172. https://doi.org/10.1109/ICSMC.2011.6083660

Li, D. \& Santos, Jr., E. (2012). Argument Formation in the Reasoning Process: Toward a Generic Model of Deception Detection. Proceedings of the EACL 2012 Workshop on Computational Approaches to Deception Detection, 63-71. ISBN 978-1-937284-19-0

Mann, S., Vrij, A., \& Bull, R. (2002). Suspects, lies and videotape: An analysis of authentichigh-stakes liars. Law and Human Behavior, 26, 365-376. https://doi.org/10.1023/A:1015332606792

Mehrabian, A. (1971). Nonverbal betrayal of feeling. Journal of Experimental Research in Personality, 5(1), 64-73.

Mihalcea, R. \& Strapparava, C. (2009). The lie detector: Explorations in the automatic recognition of deceptive language. Proceedings of the ACL-IJCNLP 2009 Conference Short Papers, 309-312. https://doi.org/10.3115/1667583.1667679

Newman, M.L., Pennebaker, J.W., Berry, D.S., \& Richards, J.M. (2003). Lying Words: Predicting Deception from Linguistic Styles. Personality and Social Psychology Bulletin, 29(5), 665675. https://doi.org/10.1177/0146167203029005010

Niedenthal, P., Barsalou, L., Winkielman, P., Krauth-Gruber, S., \& Ric, F. (2005). Embodiment in Attitudes, Social Perception, and Emotion. Personality and Social Psychology Review, 3(9), 184-211. https://doi.org/10.1207/s15327957pspr0903_1

Pennebaker, J.W., Mehl, M.R., \& Niederhoffer, K.G. (2003). Psychological aspects of natural language use: Our words, our selves. Annual Review of Psychology, 54, 547-577. https://doi. org/10.1146/annurev.psych.54.101601.145041

Peucheret, F. (2014). Du mensonge à l’aveu. Paris, France: Amentys Éditions.

Porter, S. \& Yuille, J.C. (1996). The language of deceit: An investigation of the verbal clues to deception in one interrogation context. Law and Human Behavior, 20, 443-459. https://doi. org/10.1007/BF01498980

Sapir, A. (1996). The L.S.I. course on scientific content analysis SCAN workbook. Phoenix, AZ: Laboratory for Scientific Interrogation. 
Skowronski, J.J., Betz, A.L., Thompson, C.P., \& Shannon, L. (1991). Social memory in everyday life: Recall of self-events and other-events. Journal of Personality and Social Psychology, 60, 831-843. https://doi.org/10.1037/0022-3514.60.6.831

Sporer, S.L. \& Schwandt, B. (2007). Moderators of nonverbal indicators of deception. Psychology, Public Policy \& Law, 13, 1-34. https://doi.org/10.1037/1076-8971.13.1.1

Talmy, L. (1985). Lexicalization patterns: semantic structure in lexical forms. In T. Shopen (Ed.), Language typology and syntactic description, vol. III: Grammatical categories and the lexicon, (pp. 57-149). Cambridge, England: Cambridge University Press.

Tekin, S., Granhag, P.A., Strömwall, L., Giolla, E.M., Vrij, A., \& Hartwig, M. (2015). Interviewing strategically to elicit admissions from guilty suspects. Law and Human Behaviour, 39, 244-252. https://doi.org/10.1037/lhb0000131

Vrij, A. (2000). Detecting lies and deceit: The psychology of lying and the implications for professional practice. West Sussex, England: John Wiley \& Sons.

Vrij, A. (2005). Criteria-Based Content Analysis: A qualitative review of the first 37 studies. Psychology, Public Policy \& Law, 11, 3-41. https://doi.org/10.1037/1076-8971.11.1.3

Vrij, A. (2008). Detecting lies and deceit: Pitfalls and opportunities. Chichester, England: John Wiley \& Sons.

Walczyk, J.J., Roper, K.S., Seemann, E., \& Humphrey, A.M. (2003). Cognitive mechanisms underlying lying to questions: Response time as a cue to deception. Applied Cognitive Psychology, 17, 755-774. https://doi.org/10.1002/acp.914

Weiss, H.M. \& Cropanzano, R. (1996). Affective Events Theory: A theoretical discussion of the structure, causes and consequences of affective experiences at work. In B.M. Staw \& L.L. Cummings (Eds.), Research in organizational behavior: An annual series of analytical essays and critical reviews, 18, 1-74. US: Elsevier Science/JAI Press.

Whorf, B.L. (1956). Language, thought, and reality: Selected writings of Benjamin Lee Whorf [ed. by John B. Caroll]. Cambridge, England: The MIT Press.

Zhou, L., Burgoon, J.K., \& Twitchell, D. (2003). A longitudinal analysis of language behavior of deception in e-mail. Proceedings of the First NSF/NIJ Symposium on Intelligence and Security Informatics, Tucson, AZ. Berlin, Germany: Springer-Verlag, 102110. https://doi. org/10.1007/3-540-44853-5_8

Zuckerman, M., DePaulo, B.M., \& Rosenthal, R. (1981). Verbal and nonverbal communication of deception. In L. Berkowitz (Ed.). Advances in experimental social psychology, 14, 1-59. https://doi.org/10.1016/S0065-2601(08)60369-X

Original manuscript received December 07, 2018 Revised manuscript accepted January 10, 2019 First published online February 15, 2019

To cite this article: Fekete, G. (2019). Information-processing in French adults practicing deception. Psychology in Russia: State of the Art, 12(1), 31-48. DOI: 10.11621/pir.2019.0103 